ment. Indeed, by incisively relating his own ideas to the stand taken by others in the field Dr. Abdel-Fadil has made an important contribution to that dialogue.

Alfred Zauberman

London School of Economics

\title{
THE STRUCTURE OF THE SOVIET ECONOMY: ANALYSIS AND RE- CONSTRUCTION OF THE 1966 INPUT-OUTPUT TABLE. By Vladimir G. Treml et al. New York: Praeger Publishers, 1972. xxiv, 660 pp. $\$ 15.00$.
}

In 1966 Treml published a reconstruction of the first Soviet input-output table. It was a pioneering effort, but specialists found it difficult to follow the detailed procedures whereby missing data of various kinds had been estimated. In the book under review, Treml and his associates present a reconstruction of the 1966 input-output table. They have clearly responded to earlier criticism, because the greater part of the work is a detailed account of the successive steps followed in the reconstruction, the sources of supplementary material, and the reliability of the resulting estimates. It is a model of clarity; but it is very much a work for the specialist.

Successive chapters set out in great detail the procedures used in deriving estimates of labor inputs, foreign trade flows, gross value of output, and final demand. This material is highly valuable to the specialist because it enables him to assess the reliability and coherence of the table, but it is heavy going for the general reader. The book also contains an interesting discussion of the role and development of input-output analysis in the Soviet Union. What it lacks is an analysis of the economy through the table-that is, the 1966 input-output table is presented, but no attempt is made to derive any conclusions about economic efficiency or structural peculiarities. No attempt is made to compare the 1959 and 1966 tables, or to infer anything about changes in structure, resource use, and so forth, from the relatively extensive and fascinating material that $\mathrm{Treml}$ and his associates have given us.

This is unfortunate, because analysis is precisely what the general reader would expect to find in a book on the structure of the Soviet economy. Although it is essential that sources and methods be clearly explained, the input-output table and its reconstruction cannot be viewed as an adequate end-product of research. It is only worthwhile, as Treml himself points out, for the light it sheds on economic interactions and economic interrelationships in the Soviet Union. Without analysis, the reconstructed table is in danger of becoming a white elephant. Treml and his associates, having published reconstructions of both the 1959 and 1966 tables, are in a better position to undertake that analysis than most other Soviet economic specialists. They are familiar with the sources, the technique, and the limitations of their reconstruction. Perhaps they will still undertake it.

Despite these deficiencies, The Structure of the Soviet Economy provides a valuable addition to our knowledge of the USSR. It is clearly written, wellorganized, and provides a considerable amount of useful information. We should be grateful to Treml and his associates for undertaking the time-consuming task of collecting, collating, and publishing the material. 